ing, moral instruction and repeated terms of imprisonment have accomplished little in that respect. If you can devise any other mode of punishment and reformation that would be more effectual than the one you criticise, I would be glad to know it, and no one would hail it with greater pleasure than myself. "The congenital criminal is a moral imbecile; no amount of punishment will ever evolve in his brain any idea of morality. This is an established fact and can not be gainsaid. He is dangerous. What shall we do with him?" I have long since passed the allotted limit of human life and have served continuously in the ranks of the profession for over sixty-five years. I have retired from it to seek the rest and quiet which age usually demands. If you desire to pursue this subject I trust you will meet with a younger and better equipped antagonist than myself, as I have neither the time or the inclination to engage in further controversy.

Robert Boal, M.D.

\section{The Relief of Abdominal Pains.}

ELKHART, IND., October 1, 1894.

To the Editor:-In answer to J. Lue Sutherland's case reported in the Journal of September 29, the Doctor asks? Was it a case of subacute peritonitis? It may have become so; for, nearly five weeks intervened from time of first attack of pain until death ensued; giving ample time for inflammation to occur, if the first cause of trouble was not promptly removed. Too often the physician's sympathy is enlisted by the entreaties of the patient for relief of pain, so that the proper means to remove the cause is not employed at once. And this is the suggestion I would make in this class of cases: If pain and distress is in gastric region give an emetic; if in lower abdomen, thoroughly empty the rectum and colon by a warm water enema, and then if there is no relief, give a quick active purgative of sulph-mag., castor oil, senna, or seidlitz powder followed within two hours by an enema, and thus remove the cause, or at least satisfy yourself that the contents of the primie $v i x$ is not the cause of the mischief. One may ask, But while removing cause how can you relieve suffering? I answer, If pain is due to acridity of contents, dilution of same by emetic, enema, or physic will often relieve pain. We can also add a few grains of bi. carb, potass. or soda in solution to the agent used to relieve; also we can use well known external applications; such as warmth to feet, cold to head, sinaprisms, warm or hot baths, hot packs or steeps. Employ these until the evacuants act. In no case give an opiate or astringent anodyne until we are convinced that the alimentary canal is empiy: Then we may not need an anodyne. Follow the foregoing procedure by carefully selected ingesta and we will realize a happy result in nearly all such cases. Respectfully, J. A. Work, M.D.

The Blessings of Co-operation.

$$
\text { St. Libory, Ilit., Sept. 28, } 1894 .
$$

To the Editor:--I congratulate you and the JoLRNAL of THE American Medical Association upon entering your new quarters on Fifth Avenue, where room, conveniences and surroundings will be much more desirable. I would like to see the day when every worthy physician of America shall become a member of the American Meprcal Association, and the Journal making weekly visits to each office. If there is any good reason why any member of the fraternity should withhold his name, himself and his skill, knowledge and influence from the Association I can not imagine what it is.

The one thing above all others, so much needed in the profession is coopperation. If the faculty throughout the country will come into the Association, the long felt need of coïperation will be established, and the means of communication through the Journal will be perfect. Thus once united, it will be quite within the reach of the Association to classify the membership for the duties of careful and thorough scientific work.

If once united and properly classified, the work that could be accomplished within the six remaining years of this century would eclipse the achievements of the past ages.

Will the day ever dawn when men can and will rise above selfishness and self-interest-above their pocket-books, and like true men labor for the true and best interests of the medical profession, and the people at large?

Is it possible that ignorance and prejudice can not be expunged from our midst? Away with them, and let the sunlight of confidence reign throughout the profession.

Invoking for you and the Associntiox all possible success, and the blessings of Heaven, I am, Very truly, Jas. Osbourne De Courcy, M.D.

\section{The Hechanical Appearance of the Journal of the American} Modical Association.

\section{A ustin, Texas, Sept. 25, 1894.}

To the Editor:-Our Journal of September 22 tells the good news-of permanent advantages in publication. Allow me to congratulate you, and all the good doctors of the United States. When Dr. Hart came to the United States, some time ago, and gave us much-esoteric and exoteric-valuable information, on the momentous question, "just how to run a journal," he forgot the mechanical part. His small print, on poor thin paper, is a great trial to doctors eyes, and a punishment they do not merit; they pay him for something far better. The (Wakele's) Lancet, is just a little better; but it too is abominably bad print; its "export" edition specially bad, with its very thin paper and small print, Our Jocrnal shows them the superior larger print and better paper, and has the appreciative thanks of American doctors.

Is it not strange, that these two great metropolitan English journals, with their princely incomes, able management, large circulation and long experience, should continue to issue such miserable print? Even the trade journals, and cheapest periodicals, of the United States, are far better printed than the British Medical Journal, and the London Lancet. Can't you prod them up?

Yours truly,

Q. C. Smith, M.D.

\section{PUBLIC HEALTH.}

Taxes for Disinfection.-Progres Medical reports that a tax has been voted in Paris to defray the expenses of cremating infected clothing, etc., and of disinfecting bouses during an epidemic or the occurrence of a contagious disease. The tax is progressive and graded according to the furnishings of the house, the minimum value being 800 francs-below that being exempt-and the maximum 20,000 francs. The tax ranges from 5 to 200 francs and defrays the expenses for the whole course of the epidemic or disease, no matter how many cases require disinfection.

Typhoid Fever.-Aside from the increase of diphtheria, elsewhere noted, and the prevalence of typhoid fever in many sections, the public health conditions remain favorable. Thus far smallpox has not increased to the extent that was apprehended on the approach of cold weather. There has been a brisk outbreak of typhoid in the garrison at Fort Sheridan, the disease supposed to have been contracted by the troops while on duty during recent labor disturbances. 